\title{
income mobility
}

Income mobility means different things to different people. This article explains the six different mobility concepts used in the literature, reviews the various indices used in the mobility literature to measure these concepts, summarizes the difference the use of different mobility concepts and measures makes in practice, presents the axiomatic approach to income mobility, and discusses a number of other issues that arise in the mobility literature.

What is income mobility? Extensive surveys of the income and earnings mobility literatures may be found in Atkinson, Bourguignon, and Morrisson (1992), Maasoumi (1998), Solon (1999), and Fields and Ok (1999a). ('Income' refers to income from all sources while 'earnings' refers to income earned in the labour market.) Mobility analysts agree on one defining feature: 'income mobility' is about how much income each recipient receives at two or more points in time. In this way, income mobility studies are distinguished from studies of the inequality and poverty aspects of income distribution, both of which are based (typically) on anonymous cross sections or (less frequently) marginal distributions of the joint distributions.

The following notation is used throughout this article. Let $x=\left(x^{1}, \ldots, x^{n}\right)$ denote a vector of 'incomes' in an initial year. This vector is 'personalized' in the sense that the same recipient units are followed over time. It is conventional to array the recipients in the base year from lowest income to highest. Whether this convention is followed or not, it is essential to keep the same order for subsequent years (or generations). Denote the ordered vector in a subsequent year by $y=\left(y^{1}, \ldots, y^{n}\right)$. The micro-mobility data, also termed in the literature the pattern of 'distributional change', is summarized by the transformation $x \rightarrow y$ in the two-period case or more generally the transformation $x \rightarrow y \rightarrow z \rightarrow \ldots$ in the T-period case. The extent of mobility associated with the transformation $x \rightarrow y$ will be denoted by $m(x, y)$.

Beyond agreeing that income mobility studies are about transformations of the type $x \rightarrow y$ or $x \rightarrow y \rightarrow z \rightarrow \ldots$, the literature is marked by considerable disagreement. This is because the term 'income mobility' connotes precise but different ideas to different researchers. It is for this reason that mobility analysts often have trouble communicating with each other, with other social scientists, or with the general public. Furthermore, these differences in notions of what income mobility is remain even after agreement is reached on a number of other aspects of the mobility under consideration. These other aspects, discussed in the following paragraphs, are whether the context is intergenerational or intragenerational, what the indicator of social or economic status is, and whether the analysis is at the macro-mobility or micro-mobility level.

One issue is whether the aspect of mobility of interest is intergenerational or intragenerational. In the intergenerational context, the recipient unit is the family, specifically a parent and a child. In the intragenerational context, the recipient unit is the individual or family at two different dates. The issues discussed in this article apply equally to both.

Second, agreement must be reached on an indicator of social or economic status and the choice of recipient unit. For brevity, I shall talk about mobility of 'income' among 'individuals'.

Third, the mobility questions asked and our knowledge about mobility phenomena may be grouped into two categories, macro and micro. Macromobility studies start with the question, 'How much economic mobility is there?' Answers are of the type ' $a$ per cent of the people stay in the same 
income quintile', ' $b$ per cent of the people moved up at least $\$ 1,000$ while $c$ per cent of the people moved down at least \$1,000', 'the mean absolute value of income change was $\$ d$,' and 'in a panel of length $\mathrm{T}$, the mean number of years in poverty is $t^{*}$.' The macro-mobility studies often go beyond this question to ask, 'Is economic mobility higher here than there and what accounts for the difference?' Answers would be of the type, 'economic mobility has been rising over time', ' $A$ has more upward mobility than $B$ because economic growth was higher in $A$ than in $B$ ', and 'incomes are more stable in $C$ than in $D$ because $C$ has a better social safety net'. Micro-mobility studies, on the other hand, start with the question, 'What are the correlates and determinants of the income or positional changes of individual income recipients?' The answers to these questions would be of the type, 'unconditionally, income changes are higher for the better-educated' and 'other things equal, higher initial income is associated with lower subsequent income growth'.

These three issues - intergenerational versus intragenerational, changes in the distribution of what among whom, and macro-mobility versus micromobility - help determine which kind of mobility analysis is being undertaken. Yet major differences remain. It is to these that we now turn.

\section{Mobility concepts and measures}

At least 20 mobility measures have been used in the literature. Many empirical mobility studies divide base- and final-year incomes into quantiles (for example, quintiles or deciles) and calculate immobility ratios, mean upward movements, and the like (Fields, 2001). Other studies estimate correlation coefficients between base-year and final-year incomes (Atkinson, Bourguignon and Morrisson, 1992). In the intergenerational mobility literature, it is common to calculate intergenerational elasticities, that is, the coefficient obtained when the logarithm of the child's income is regressed on the logarithm of the parent's (Solon, 1999).

In each case, we may ask, what are the various measures measuring? The essential answer is this: different indices measure different underlying entities. Whenever one of these underlying entities is measured, other information contained in the joint distribution of initial and final incomes is lost.

What are the different underlying entities that the various income mobility measures measure? The first distinction to be drawn is between measures of time independence and measures of movement. The question asked by timeindependence studies is, how dependent is current income on past income? One commonly used measure of time independence is the beta coefficient commonly calculated in the intergenerational mobility literature by regressing the log-income of the child on the log-income of the parent.

Movement studies ask a different question, namely: in comparisons of incomes of the same individuals between one year and another, or of parents and children between one generation and another, how much income movement has taken place? The various movement indices in the literature may usefully be classified into five categories or concepts ('concepts' because they are different underlying entities, not alternative measures of the same underlying entity).

Positional movement (or 'quantile movement') is about the movement of individuals among various positions (quintiles, deciles, centiles, or ranks) in the income distribution. An individual experiences positional movement if and only if he or she changes quintiles, deciles, centiles, or ranks. Positional movement in a population is greater the more such positional changes there 
are and/or the larger these positional changes are. King (1983) derived a broad class of positional movement indices axiomatically, one member of which is

$$
M_{K}(x, y)=1-\exp \left[-\frac{\gamma}{n} \sum_{i=1}^{n} \frac{\left|z_{i}-y_{i}\right|}{\mu(y)}\right],
$$

where $\gamma$ is the observer's degree of immobility aversion, $z_{i}$ is the income level agent $i$ would have obtained if his or her rank order did not change during the process $x \rightarrow y$, and $\mu(y)$ is the mean income in distribution $y$.

Like positional movement, share movement is relative but it is relative in a different way. Share movement takes place if and only if an individual's income rises or falls relative to the mean. Thus, an individual can experience upward or downward share movement even if his or her income in dollars is unchanged and/or if he or she does not change position within the income distribution. Share movement in the population reflects the frequency and magnitude of these individual share changes. One attractive index of share movement in a population is the mean absolute value of share changes

$$
M_{S}(x, y)=\frac{1}{n} \sum_{i=1}^{n}\left|\frac{y_{i}}{\mu_{y}}-\frac{x_{i}}{\mu_{x}}\right|,
$$

where $\mu(x)$ and $\mu(y)$ are the means of distributions $x$ and $y$ respectively.

Another concept is non-directional income movement (also called 'flux'), which gauges the extent of fluctuation in individuals' incomes. To illustrate, suppose that in a two-person economy one person's income goes up by $\$ 10,000$ while another's goes down by $\$ 10,000$. Those who see an average income change of $\$ 10,000$ are non-directional income movement adherents. Two indices of non-directional income movement have been suggested by Fields and Ok (1996; 1999b):

$$
M_{F-O_{1}}(x, y)=\frac{1}{n} \sum_{i=1}^{n}\left|y_{i}-x_{i}\right|
$$

and

$$
M_{F-O_{2}}(x, y)=\frac{1}{n} \sum_{i=1}^{n}\left|\log y_{i}-\log x_{i}\right| .
$$

Suppose, however, that, when one person's income goes up by $\$ 10,000$ and another's goes down by $\$ 10,000$, the observer cares not only about the amounts of the income changes but also about their direction. Directional income movement may be judged using a linear or a concave valuation function. One valuation function which embodies concavity is the mean change in log-incomes (Fields and Ok, 1999):

$$
M_{F-O_{3}}(x, y)=\frac{1}{n} \sum_{i=1}^{n}\left(\log y_{i}-\log x_{i}\right) .
$$

As a fifth and final notion of income movement, consider how the income changes experienced by individuals cause the inequality of longer-term incomes to differ from the inequality of base-year incomes. Mobility as an equalizer of longer-term incomes would judge that a pattern of income change $(1,3) \rightarrow(1,5)$ would disequalize longer-term income relative to the base, while a pattern of income change $(1,3) \rightarrow(5,1)$ would equalize longer-term income relative to the base. This concept is well-established in the literature (Schumpeter, 1955; Shorrocks, 1978b; Atkinson, Bourguignon, and Morrisson, 1992; Slemrod, 1992; Krugman, 1992; Jarvis and Jenkins, 1998), but 
only recently has a class of measures of this concept been proposed (Fields, 2005). One family within this class is

$$
\mathscr{E} \equiv 1-(I(a) / I(x))
$$

where $x$ is the vector of base-year incomes, $y$ is the vector of final-year incomes, $a$ is the vector of average incomes, the i'th element of which is $a^{i} \equiv \frac{x^{i}+y^{i}}{2}$, and $I($.) is a cross-sectional inequality measure such as the Gini coefficient or the Theil index.

We thus have six mobility concepts and a large number of measures. Because these concepts are fundamentally different from one another, it is important for analysts to choose the concepts that are of greatest interest to them and then measure those concepts. Let us now turn to a brief empirical review of studies that have used two or more of these concepts.

\section{Different mobility concepts in practice}

The previous section distinguished between time independence, positional movement, share movement, non-directional income movement, directional income movement, and mobility as an equalizer of longer-term incomes. How do these six concepts and the measures of them compare in empirical work? Specifically, which country has more mobility than another? Has mobility been rising or falling over time within a country? Are some groups in the population more or less mobile than others?

The answers to these questions have been shown empirically to depend on which mobility concept is used. In comparing OECD countries, some countries were found to be more mobile than others with the use of measures of some concepts and less mobile than others with the use of measures of other concepts (OECD, 1996; 1997). When we looked over time, in the United States measures of four concepts (time independence, positional movement, share movement, and income flux) all peaked in 1980-5 but measures of two other concepts did not: directional income movement exhibits a saw-tooth pattern, while mobility as an equalizer of longer-term incomes exhibits a peak followed by a valley (Fields, Leary and Ok, 2002; Fields, 2005). In France, mobility differences among demographic groups have been explored (Buchinsky et al., 2004). The answers to the questions 'Who has more mobility: women or men? Better-educated or less-educated workers?' were shown to differ depending on which mobility concept was used. By gender, women in France have more time independence and positional movement than men, less share movement than men, about the same non-directional and directional movement in logs, and about the same amount of mobility as an equalizer of longer-term incomes. By education, those with the highest educational attainments have less time independence and positional movement, and if anything more share movement, flux, and directional income movement in logs. In Argentina, too, measures of the six different concepts produced qualitatively different results (Sánchez Puerta, 2005). Looking at changes over time, some mobility indices increased, some decreased, and some showed no clear trend. Comparing population subgroups (genders, educational levels, age ranges, regions, initial quintiles, and initial sector), some groups were found to have higher earnings mobility for some concepts and lower earnings mobility for others; no group was found to have higher mobility than others for every mobility concept. Finally, in both Venezuela and Mexico, the time trend of mobility was found to vary according to the notion of mobility measured (Freije, 2001; Duval Hernández, 2005). 
The conclusion is that at both levels, macro and micro, it makes an important qualitative difference which mobility concept is being gauged. When a layperson asks an economist which of two situations is the more mobile, the answer 'It depends' is not very satisfying. An answer of the type 'Current incomes are more dependent on past incomes in the United Kingdom than in the United States (that is, the UK is less mobile in this respect than the USA), but the United Kingdom has more quintile movement than the United States (and therefore is more mobile than the USA in this sense)' is more informative, even if less clear-cut than the questioner may have been hoping for.

\section{The axiomatic approach to income mobility}

We have seen that there are different income mobility concepts and that the indices measuring these concepts behave differently from one another. How is the analyst to decide which notion(s) best capture(s) the essence of 'income mobility' for him or her? One approach is to proceed axiomatically, that is, to say that 'for me, mobility is such and such' and then to see which concepts, if any, embody these axioms.

Two broad approaches to axiomatization may be found in the literature. In one approach, mobility is conceptualized in social welfare terms (Atkinson, 1980; King, 1983; Chakravarty, Dutta and Weymark, 1985; Dardanoni, 1993; Gottschalk and Spolaore, 2002; Ruiz-Castillo, 2004). In the other, a descriptive approach is used, wherein analysts specify the properties they wish income mobility concepts and measures to possess, and then proceed to deduce which indices, if any, have these properties (Cowell, 1985; Fields and Ok, 1996; 1999b; D’Agostino and Dardanoni, 2005). The work of Shorrocks (1978a; 1978b) makes use of both of these approaches. This difference between the ethical and the descriptive axiomatizations in the mobility literature parallels the two strands of the inequality literature (Foster and Sen, 1997): for Atkinson (1970), inequality is the amount of social welfare lost because incomes are distributed the way they are rather than being distributed perfectly equally, whereas for Sen (1973, p. 2), inequality is objective in the sense that "one can distinguish between $(a)$ "seeing" more or less inequality, and $(b)$ "valuing" it more or less in ethical terms'. Note that under both the ethical and the descriptive approaches the amount of mobility recorded has or may have welfare significance. For example, many observers would say that an economy with more directional income movement has performed better than an economy with less directional income movement.

The literature offers a wide variety of axioms, some of which were designed with particular mobility concepts in mind, others of which have been explored to help sharpen what is meant by 'mobility'. Shorrocks (1993) presents 12 axioms for mobility and shows that they are mutually incompatible. In view of their incompatibility, there is a need for judgements as to which ones an analyst wants a measure to embody.

Fields and Ok (1999a) and Fields (2001) have suggested that analysts choose among the axioms by considering their views on simple examples. For example, consider the following three situations:

$$
\begin{array}{cl}
\text { I }: & (1,3) \rightarrow(1,3) \\
\text { II }: & (1,3) \rightarrow(2,6) \\
\text { III }: & (2,6) \rightarrow(4,12)
\end{array}
$$

and the corresponding degree of mobility $m(x, y)$. (As above, $\rightarrow$ denotes a 
change in the ordered (personalized) vector of incomes.) The axiom of strong relativity, if accepted, would maintain that $m(\lambda x, \alpha y)=m(x, y)$ for all $\lambda, \alpha>0$ and all $x, y \in \Re_{+}^{\mathrm{n}}$. If strong relativity is accepted, it requires that Situations I, II, and III all have the same mobility. In Situation I, the only sensible amount of mobility for there to be is zero, and therefore strong relativity requires that Situations II and III also have zero mobility. An analyst who sees non-zero income mobility in Situations II and III is therefore not a strong relativity adherent.

Similarly, (weak) relativity specifies that $m(\lambda x, \lambda y)=m(x, y)$ for all $\lambda>0$ and all $x, y \in \Re_{+}^{\mathrm{n}}$. This axiom requires that Situations II and III have the same mobility, though not necessarily the same mobility as Situation I. Therefore, an analyst who sees more mobility in Situation III than in Situation II is not a (weak) relativity adherent either.

The literature offers characterizations of some of the mobility measures that have been used - for example, Fields and Ok's (1996; 1999b) measures of non-directional and directional income movement and Chakravarty, Dutta and Weymark's (1985) index of mobility as welfare change. More commonly, though, the axioms are used to state a number of desirable properties and then display a measure or a family of measures consistent with these properties.

In summary, a fruitful way for the analyst to choose which mobility concept(s) is (are) most salient for oneself is to consider the axiomatic judgements underlying each of the concepts. To date, some but not all of the income mobility concepts have been so characterized.

\section{Other issues}

The income mobility literature has a number of other issues that remain more or less contentious, not because the different views have not been worked out but because different analysts hold genuinely different positions on a number of important matters.

\section{Is all distributional change 'mobility' or only some of it?}

Lurking in the background of some writings on income mobility is a fundamental difference of opinion about what income mobility is. For the majority of analysts, the notion of 'income mobility' has both absolute and relative components. For example, if all incomes double, most would judge there to be more mobility than if all incomes remain unchanged. For some analysts, though, the notion of 'income mobility' is relative only; therefore, the change in the mean needs to be taken out, and 'mobility' applies only to what is left.

Thinking of 'mobility' in this way can lead to some controversial judgements. For example, Chakravarty, Dutta and Weymark (hereafter CDW) (1985) propose the following mobility index:

$$
M_{C D W} \equiv\left(E\left(y_{\text {agg }}\right) / E(b)\right)-1,
$$

where $E($.$) is an equality measure, y_{\text {agg }}$ is a vector of aggregate incomes over the observation period, and $b$ is the benchmark vector of incomes under the assumption of complete relative immobility following the first period. In the case in which $E($.$) is a relative equality measure, the term E(b)$ is replaced by $E(x)$, where $x$ is the vector of first-period incomes. In the view of these authors (CDW, 1985, p. 8): 'Socially desirable mobility is associated with 
income structures having positive index values while socially undesirable mobility is associated with income structures having negative index values.' Thus, given their index, CDW judge that mobility contributes positively to social welfare if and only if $y_{a g g}$ is distributed more equally than $x$. Thus, if all incomes rise but the percentage gains are larger at the top end of the income distribution than they are at the bottom, mobility would be judged by CDW to have been socially undesirable, in direct contradiction to the quasi-Paretian welfare judgement that an increase in some incomes with no decline in others raises social welfare. This difference of views - whether 'income mobility' includes the growth aspect of distributional change or whether 'mobility' is what remains after growth has been taken out - underlies much of the mobility literature, but rarely is it made explicit.

\section{What is 'relative mobility'?}

As already noted, the term 'relative mobility' is used ambiguously, sometimes to refer to mobility notions characterized by strong relativity $m(\lambda x, \alpha y)=$ $m(x, y)$ for all $\lambda, \alpha>0$ and all $x, y \in \Re_{+}^{\mathrm{n}}$ and sometimes to refer to those characterized by weak relativity $m(\lambda x, \lambda y)=m(x, y)$ for all $\lambda>0$ and all $x, y \in \Re_{+}^{\mathrm{n}}$. Note that for both of these relativity notions the basis for determining whether a given individual is experiencing upward or downward relative mobility is that individual's change in income relative to the income changes of others.

However, the term 'relative mobility' is used in yet another sense, namely, to refer to positional movements. On this view, an individual experiences relative mobility if and only if he or she changes position (quintile, decile, centile, or rank) from base year to final year. For example, Jenkins and Van Kerm (2003) break down trends in income inequality into a 'pro-poor income growth' component and an 'income mobility' component. The 'income mobility' component involves re-rankings and only re-rankings. Thus, for them as for some others, mobility is positional movement and nothing more.

Finally, D'Agostino and Dardanoni (2005) have yet a different definition of relative mobility. For them, relative mobility involves a change in an individual's relative standing with respect to all others, whereas absolute status is something that can be derived by looking at data regarding the individual taken in isolation.

This last point raises the issue of what is meant by 'absolute mobility,' to which we now turn.

\section{What is 'absolute mobility'?}

The term 'absolute mobility' is used in at least three different ways in the income mobility literature. One way is to express a concern with gains and losses of income rather than income shares or positions. In this sense, the concept of directional income movement and the various measures of that concept are about absolute mobility. Second, 'absolute mobility' is sometimes used to mean that the analyst is concerned with the absolute value of income changes, as would be the case in studies of non-directional income movement, or flux. Third, the term is used in the sense of translation invariance, in the sense that, if all initial and final incomes are increased by the same amount, the new situation has the same absolute mobility as the original one, that is, $m(x+\alpha, y+\alpha)=m(x, y)$. 
As is the case elsewhere in economics, when a term has more than one meaning within the same literature, it is probably best to drop the term altogether. Henceforth, researchers would do better to speak of dollar-based, absolute-value-based, or translation-invariant income mobility measures in preference to 'absolute mobility'.

\section{Is 'income mobility' decomposable, and if so, how?}

Consider the total income mobility recorded in a population. Under what circumstances can the total be broken down into component parts?

Of the six income mobility concepts considered above, one involves the time-independence aspect of mobility and the other five involve the movement aspect of mobility. The time-independence aspect of mobility is not decomposable. However, there have been decompositions of various movement measures.

One type of decomposition is subgroup decomposability, that is, if the population is divided into $\mathbf{J}$ subgroups, the total income mobility in the population as a whole equals a (possibly) weighted average of the mobility in each of the subgroups:

$$
m(x, y)=\sum_{j=1}^{J} w_{j} m_{j}(x, y) .
$$

A number of income mobility measures are subgroup decomposable; examples are Fields and Ok's (1996; 1999b) non-directional income movement measures

$$
\begin{aligned}
m_{1}(x, y) & \equiv \frac{1}{n} \sum_{i=1}^{n}\left|y_{i}-x_{i}\right| \\
\text { and } \quad m_{2}(x, y) & \equiv \frac{1}{n} \sum_{i=1}^{n}\left|\log y_{i}-\log x_{i}\right|
\end{aligned}
$$

and their directional income movement measure

$$
m_{3}(x, y) \equiv \frac{1}{n} \sum_{i=1}^{n}\left(\log y_{i}-\log x_{i}\right) .
$$

A second kind of decomposition is into substantively meaningful components. There is a long tradition in the sociology literature (for example, Bartholomew, 1982) of breaking down the movement of individuals among occupations or social classes into two component parts: $(a)$ changes that can be attributed to the increased availability of positions in the better occupations and social classes ('structural mobility') and (b) changes that can be attributed to increased movement of individuals among occupations and social classes for a given distribution of positions among these classes ('exchange mobility'). Bridging the economics and sociology literatures, Markandya $(1982 ; 1984)$ proposes two alternative decompositions of income mobility along these lines. The first defines exchange mobility as the proportion of the change in welfare that could have been obtained if the income distribution had stayed constant through time, in which case structural mobility is defined as the residual welfare change. The second defines structural mobility as the change in welfare that would have taken place if the twoperiod or two-generation transition matrix had exhibited complete immobility, in which case exchange mobility is defined as the residual. Along similar lines, Ruiz-Castillo (2004) shows how the CDW (1985) index of wel- 
fare due to mobility could be decomposed into either $(a)$ a precisely defined structural component and a residual representing exchange mobility or $(b)$ a precisely defined exchange component and a residual representing structural mobility. In all these cases, the residual component makes the decomposition exact but in a rather unexciting way.

The results just cited do not mean that an exact additive decomposition of income mobility is impossible. Fields and Ok (1996) show that their mobility index $m_{1}(x, y) \equiv \frac{1}{n} \sum_{i=1}^{n}\left|y_{i}-x_{i}\right|$ is decomposable into the sum of appropriately defined structural and exchange components. In the case of a growing economy, the decomposition equation is $m_{1}(x, y)=\left(\sum_{i=1}^{n} y_{i}-\sum_{i=1}^{n} x_{i}\right)+2 \sum_{\left\{i: y_{i}<x_{i}\right\}}\left(x_{i}-y_{i}\right)$. An analogous decomposition holds for a contracting economy. Along similar lines, Fields and Ok (1999b) show that their directional movement measure $m_{3}(x, y) \equiv \frac{1}{n} \sum_{i=1}^{n}\left(\log y_{i}-\log x_{i}\right)$ is decomposable into social utility growth and social utility transfer components. In all of these cases, the weakness of Markandya's and Ruíz-Castillo's residual approaches is averted.

\section{What other empirical issues arise?}

Empirical researchers should bear in mind two additional issues. One is that, as an empirical matter, the longer the observation period, the greater is the amount of mobility registered (Atkinson, Bourguignon and Morrisson, 1992). Therefore, care should be taken not to compare, for example, twoyear mobility in one context with, for example, five-year mobility in another.

Second, measurement error is a serious issue. There is an ample literature on mismeasurement of earnings levels but, as yet, only a very limited literature on mismeasurement of earnings changes (Deaton, 1997; Bound, Brown and Mathiowetz, 2001). A task for the future is to estimate empirically the effect of measurement error on estimates of both macro-mobility and micromobility.

\section{Conclusions}

The income mobility literature is fundamentally unsettled. This is because the very term 'income mobility' connotes different things to different people. This article has reviewed a number of dimensions in which differences arise: which of six notions most accurately captures the fundamental idea of 'income mobility', which indices best measure each of the concepts, which axioms best characterize the essence of 'income mobility', how income mobility has been evolving over time in different countries, which demographic groups have more mobility than others in different settings, and which theoretical refinements to the notion of 'income mobility' hold the greatest promise.

Given the unsettled state of the field, before researchers 'do a mobility study', it is important that we specify which concept or concepts of mobility we are considering, which measures of these concepts we are using, and which questions we are answering. More than once, when I have given seminars, a member of the audience has raised his or her hand and said, 'But that's not what mobility is'. Let us do all that we can to clarify what we are talking about so that we do not to talk past one another any more than we have to.

Gary S. Fields 


\section{See also}

inequality (measurement);

intergenerational income mobility;

longitudinal data analysis.

\section{Bibliography}

Atkinson, A. 1970. On the measurement of inequality. Journal of Economic Theory 2, 244-63.

Atkinson, A. 1980. The measurement of economic mobility. In Inkomensverdeling en Openbare Financién, ed. P. Eijgelshoen and L. van Gemerden. Utrecht: Het Spectrum.

Atkinson, A.B., Bourguignon, F. and Morrisson, C. 1992. Empirical Studies of Earnings Mobility. London: Harwood Academic Publishers.

Bartholomew, D. 1982. Stochastic Models for Social Processes. London: Wiley.

Bound, J., Brown, C. and Mathiowetz, N. 2001. Measurement error in survey data. In Handbook of Econometrics, vol. 5, ed. J. Heckman and E. Leamer. Amsterdam: North-Holland.

Buchinsky, M., Fields, G., Fougère, D. and Kramarz, F. 2004. Francs or ranks? Earnings Mobility in France, 1967-1999. Mimeo. Paris: INSEE.

Chakravarty, S., Dutta, B. and Weymark, J. 1985. Ethical indices of income mobility. Social Choice and Welfare 2, 1-21.

Chronic Poverty Research Centre. 2004. The Chronic Poverty Report 2004-05. Manchester: Chronic Poverty Research Centre.

Cowell, F. 1985. Measures of distributional change: an axiomatic approach. Review of Economic Studies 52, 135-51.

D'Agostino, M. and Dardanoni, V. 2005. The measurement of mobility: a class of distance indices. Paper presented to the Society for the Study of Economic Inequality, Palma de Mallorca, Spain, July.

Dardanoni, V. 1993. Measuring social mobility. Journal of Economic Theory 61, 372-94.

Deaton, A. 1997. The Analysis of Household Surveys. Baltimore, MD: Johns Hopkins University Press.

Duval Hernández, R. 2005. Dynamics of labor market earnings and sector of employment in urban Mexico. Doctoral dissertation, Cornell University.

Fields, G. 2001. Distribution and Development: A New Look at the Developing World. Cambridge, MA: MIT Press and Russell Sage Foundation.

Fields, G. 2005. Does income mobility equalize longer-term incomes? New measures of an old concept. Mimeo, Cornell University.

Fields, G., Leary, J. and Ok, E. 2002. Stochastic dominance in mobility analysis. Economics Letters 75, 333-9.

Fields, G. and Ok, E. 1996. The meaning and measurement of income mobility. Journal of Economic Theory 71, 349-77.

Fields, G. and Ok, E. 1999a. The measurement of income mobility: an introduction to the literature. In Handbook on Income Inequality Measurement, ed., J. Silber. Boston: Kluwer.

Fields, G. and Ok, E. 1999b. Measuring movement of incomes. Economica 66, 455-72.

Foster, J. and Sen, A. 1997. On Economic Inequality, expanded edition. Oxford: Oxford University Press.

Freije, S. 2001. Household income dynamics in Venezuela. Unpublished doctoral. dissertation, Cornell University.

Gottschalk, P. and Spolaore, E. 2002. On the evaluation of economic mobility. Review of Economic Studies 69, 191-208.

Jarvis, S. and Jenkins, S. 1998. How much income mobility is there in Britain? Economic Journal 108, 1-16.

Jenkins, S. and Van Kerm, P. 2003. Trends in income inequality, pro-poor income growth, and income mobility. Discussion Paper No. 904. Bonn: IZA.

King, M. 1983. An index of inequality, with applications to horizontal equity and social mobility. Econometrica 51, 99-115. 
Krugman, P. 1992. The rich, the right, and the facts. American Prospect 11, 19-31.

Maasoumi, E. 1998. On mobility. In Handbook of Applied Economic Statistics, ed. D. Giles and A. Ullah. New York: Marcel Dekker.

Markandya, A. 1982. Intergenerational exchange mobility and economic welfare. European Economic Review 17, 301-24.

Markandya, A. 1984. The welfare measurement of changes in economic mobility. Economica 51, 457-71.

OECD (Organisation for Economic Co-Operation and Development). 1996. Employment Outlook 1996. Paris: OECD.

OECD. 1997. Employment Outlook 1997. Paris: OECD.

Ruiz-Castillo, J. 2004. The measurement of structural and exchange mobility. Journal of Economic Inequality 2, 219-28.

Sánchez Puerta, M. 2005. Earnings mobility in urban Argentina. Unpublished doctoral dissertation, Cornell University.

Schumpeter, J. 1955. Imperialism and Social Classes. New York: Meridian Books.

Sen, A. 1973. On Economic Inequality. New York: Norton.

Shorrocks, A. 1978a. Income inequality and income mobility. Journal of Economic Theory 19, 376-93.

Shorrocks, A. 1978b. The measurement of mobility. Econometrica 46, 1013-24.

Shorrocks, A. 1993. On the Hart measure of income mobility. In Industrial Concentration and Economic Inequality, ed. M. Casson and J. Creedy. London: Edward Elgar.

Slemrod, J. 1992. Taxation and inequality: a time-exposure perspective. In Tax Policy and the Economy, vol. 6, ed. J. Poterba. Cambridge, MA: MIT Press for the NBER.

Solon, G. 1999. Intergenerational mobility in the labor market. In Handbook of Labor Economics, vol. 3, ed. O. Ashenfelter and D. Card. Amsterdam: North-Holland. 